\title{
EKSPOSISI FILIPI 2:1-11
}

\begin{abstract}
Abstrak
Tujuan surat Filipi salah satunya untuk berterima atas pemberian jemaat kepada rasul Paulus. Paulus juga mendorong mereka untuk maju dan mengenal Tuhan dalam persatuan, kerendahan hati, persekutuan dan damai sejahtera. Paulus memberikan beberapa petunjuk supaya sehati sepikir, dalam satu kasih, satu jiwa, satu tujuan, dengan tidak mencari kepentingan sendiri atau puji-pujian yang sia-sia. Paulus memberitahukan hal yang perlu diteladani dari Kristus Yesus dalam hal kerendahan hati-Nya yaitu: tidak mempertahankan kesetaraannya dengan Allah dan juga ia rela menjadi hamba yang setia dan taat kepada rencana Allah dan bahkan sampai mati di atas kayu salib. Paulus juga mengajarkan Alasan mengapa sehingga Allah sangat meninggikan Yesus dan mengaruniakan nama di atas segala Nama karena kerendahan hati-Nya.
\end{abstract}

Kata Kunci: Filipi, Kerendahan Hati, Sukacita, Teladan

\section{PENDAHULUAN}

Surat Filipi adalah surat yang ditulis oleh Paulus dengan tema "sukacita dalam hal hidup bagi Kristus." Tujuan Paulus menulis surat Filipi di antaranya adalah untuk berterima kasih kepada mereka atas pemberian yang mereka kirim kepadanya, untuk memberikan kabar kepada jemaat di Filipi tentang keberadaan paulus sekarang (dalam penjara), dan untuk mendorong mereka untuk maju dan mengenal Tuhan dalam persatuan, kerendahan hati, persekutuan dan damai sejahtera.

Jika memperhatikan tulisan Paulus ini dalam pasal 2 dan pasal 4 maka nampaknya bahwa ada permusuhan atau benih perpecahan dalam jemaat tersebut. Pasal 2:2-4 mengatakan, "karena itu sempurnakanlah sukacitaku dengan ini: hendaklah kamu sehati sepikir, dalam satu kasih, satu jiwa, satu tujuan, dengan tidak mencari kepentingan sendiri atau puji-pujian yang sia-sia. Sebaliknya hendaklah dengan rendah hati yang seorang menganggap yang lain lebih utama dari pada dirinya sendiri; dan janganlah tiap-tiap orang hanya memperhatikan kepentingannya sendiri, tetapi kepentingan orang lain juga. Selanjutnya bahwa bukti yang paling kuat bahwa dalam jemaat tersebut terjadi pertentangan antara anggota jemaat adalah pada pasal 4:2 yang mengatakan, "Euodia kunasihati dan Sintikhe kunasihati, supaya sehati sepikir dalam Tuhan." Paulus menekankan supaya jangan terjadi pertentangan di antara Jemaat. Paulus juga memberikan pengajaran agar melihat kepada Yesus Kristus yang penuh dengan kerendahan hati supaya tidak terjadi pertentangan itu

Berdasarkan hal di atas maka tulisan ini akan memberikan penjelasan tentang Filipi 2:1-11.

PENGAJARAN PENTING DARI FILIPI 2:1-11

Pada bagian ini akan memberikan beberapa pengajaran penting yang terkandung dalam Filipi 2:1-11. 


\section{Sukacita yang Sempurna}

Ayat 1 mengatakan, "Jadi karena dalam Kristus ada nasihat, ada penghiburan kasih, ada persekutuan Roh, ada kasih mesra dan belas kasihan," maka dapat dikatakan bahwa ungkapan ini sebagai landasan dari Paulus untuk memberikan nasihat kepada jemaat di Filipi. Selanjutnya dalam ayat 2 kalimat pertama, "karena itu sempurnakanlah sukacitaku dengan ini:" adalah suatu ungkapan bagaimana supaya paulus merasakan sukacita yang sempurna itu dan juga petunjuk kepada Jemaat Filipi dan juga pembaca dari surat Filipi ini bagaimana untuk mendapatkan sukacita itu. Paulus memberikan beberapa petunjuk tentang bagaimana cara mendapatkan sukacita yang sempurna itu adalah dengan cara sehati sepikir, dalam satu kasih, satu jiwa, satu tujuan, dengan tidak mencari kepentingan sendiri atau puji-pujian yang siasia. Paulus menyadari bahwa jika seseorang atau anggota jemaat tidak memiliki sifatsifat di atas, maka akan mudah terjadi perselisihan dalam jemaat. J. Wesley Brill menjelaskan sebagai berikut: sehati sepikir,satu kasih, satu jiwa dan satu tujuan. jika seseorang ada dalam Kristus, maka tentulah orang tersebut akan sehati sepikir, satu kasih, satu jiwa dan satu tujuan dengan semua orang yang juga ada dalam Kristus. Misalnya dengan satu roda yang berjari-jari banyak, di mana semakin dekat jari-jari itu ke pusat roda maka lebih rapat pula satu sama lain, demikianlah halnya dengan orang percaya bahwa jika mereka semakin dekat kepada Kristus maka semakin

erat juga hubungan dengan orang lain yang juga ada dalam Kristus. ii Selanjutnya, Paulus mengharapkan agar jemaat di Filipi tidak mencari kepentingan sendiri atau pujipujian yang sia-sia. J. Wesley Brill mengatakan,

Paulus meneruskan nasihatnya dengan suatu permohonan yang berdasarkan kasih. "dengan tidak mencari kepentingannya sendiri atau puji-pujian yang yang siasia. Hal mencari kepentingan sendiri di antara orang kristen adalah suatu penyakit yang merusakkan persatuan dan kemajuan jemaat Kristus. Sebenarnya sifat mencari kepentingan sendiri berdasarkan kesombongan, sifat menyayangi diri sendiri, dan suka meninggikan diri sendiri. Jikalau kita hanya memikirkan diri sendiri, tentu hati kita tertutup kepada keperluan-keperluan orang lain. ${ }^{\text {ii }}$

Paulus menyarankan agar jemaat yang ada di Filipi tidak mencari kepentingan diri sendiri dan pujian yang sia-sia.

Jadi jika sesorang menginginkan sukacita yang sempurna, maka ia harus mampu melakukan atau menerapkan beberapa hal yaitu: sehati sepikir, dalam satu kasih, satu jiwa, satu tujuan, dengan tidak mencari kepentingan sendiri atau puji-pujian yang sia-sia.

\section{Yesus Kristus sebagai Teladan dalam Hal Kerendahan Hati}

Paulus memberikan nasihat kepada jemaat yang ada di Filipi supaya mereka meneladani Kristus. Jemaat harus menaruh pikiran dan perasaan yang terdapat juga dalam Kristus Yesus. Jika pikiran dan perasaan sesorang ada dalam Kristus Yesus maka orang tersebut akan membuat persekutuan tetap baik karena Yesus tidak pernah menginginkan perpecahan atau kekacauan. Warren W. Wiersbe mengatakan, 
"Bagaimanapun juga, sudut pandang kita menentukan sikap dan perbuatan kita. Bila pandangan kita mementingkan diri sendiri, maka tindakan-tindakan kita akan memecah-belah dan menghancurkan; Yakobus juga mengatakan hal yang sama. (Bacalah Yakobus 4:1-10). ${ }^{\text {,iv }}$

Dalam kaitannya dengan persekutuan, paulus menyarankan agar mereka senantiasa memiliki sikap rendah hati karena dengan adanya kerendahan hati maka persekutuan akan tetap terjalin dengan baik. Alkitab penuntun mejelaskan bahwa: "bersifat renda hati berarti bahwa kita menyadari kelemahan-kelemahan kita dan dengan lekas akan menghormati Allah dan orang lain atas hal-hal yang kita kerjakan." Jika sesorang tidak memiliki kerendahan hati maka orang tersebut tidak akan menyadari kelemahan-kelemahannya dan tidak akan menghormati Allah dalam kehidupannya dan hal inilah yang bisa menghancurkan persekutuan atau jemaat.

Ada beberapa hal yang perlu diteladani dari Kristus Yesus dalam hal kerendahan hatiNya yaitu:

\section{Tidak Memepertahankan Kesetaraan-Nya dengan Allah}

Ayat 6 mengatakan, "yang walaupun dalam rupa Allah, tidak menganggap kesetaraan dengan Allah itu sebagai milik yang harus dipertahankan." Yesus tidak mempertahankan status-Nya yang sama dengan Allah melainkan Ia rela melepaskan status itu sebagai bukti kerendahan hati-Nya. Wesley Brill mengatakan,

Dalam ayat-ayat ini terlihat tabiat Tuhan Yesus, yaitu tabiat ketuhanan dan tabiat kemanusiaan. Tabiat ketuhanan dinyatakan dalam perkataan ini: 'walaupun dalam rupa Allah', yaitu mempunyai tabiat ketuhanan sebagai Anak Tunggal Allah. Ini sesuai dengan perkataan yang terdapat dalam Yohanes 1:1. Dalam Kolose 1:15, dikatakan "Ia adalah gambar Allah yang tidak kelihatan" dan perkataan dalam Ibrani 1:3 "Ia adalah cahaya kemuliaan Allah dan gambar Wujud Allah, dan dalam Yohanes 10:30 Tuhan Yesus berkata, "Aku dan Bapa adalah satu."vi

Dengan demikian maka Yesus setara dengan Allah dan Ia adalah Allah. Tetapi dalam Filipi 2:6 ini dikatakan bahwa ia tidak mempertahankan status itu melainkan rela melepaskannya demi umat manusia. Bukan berarti bahwa tabiat ketuhannya itu hilang melinkan bahwa Ia hanya membatasi diri dalam beberapa hal. Lebih lanjut J. Wesley Brill mengatakan,

Ia telah meninggalkan kemuliaan dan ketinggian-Nya. Tetapi bagaimana Ia mengosongkan diri-Nya? Adakah Ia meninggalkan KETUHANANNYA atau tabiat ketuhanan-Nya? Sekali-kali tidak. Itu mustahil. Ia adalah Allah dan Allah tidak dapat berhenti menjadi Allah. Ia tidak meninggalkan sifat-sifat Allah dan ketuhananNya. Tentu Tuhan Yesus telah mengosongkan diri-Nya daripada kemuliaan-Nya dan Ia telah membatasi diri-Nya dalam banyak hal. Ia membatasi dirinya secara tempat dan rupanya juga secara pengetahuan dan kuasa, tetapi hanya seberapa saja sebab Ia tetap memiliki pengetahuan dan kuasa yang lebih daripada manusia. ${ }^{\text {vii }}$ 


\section{Mengambil Rupa seorang Hamba}

Ayat 7 mengatakan, "melainkan telah mengosongkan diri-Nya sendiri, dan mengambil rupa seorang hamba, dan menjadi sama dengan manusia." Yesus menjadi seorang hamba adalah mungkin sesuatu yang sulit diterima oleh manusia, karena bagaimana mungkin Ia yang adalah Allah, Raja, dan Penguasa dalam waktu seketika menjadi seorang hamba? Inilah salah satu bukti bahwa Yesus benar-benar memiliki kerendahan hati. Hati seorang hamba memang Ia perlihatkan dalam kehidupanNya. Salah satu ciri yang menonjol dari seorang hamba adalah "ketaatan". Ayat 8 mengatakan, "Dan dalam keadaan sebagai manusia, Ia telah merendahkan diri-Nya dan taat sampai mati, bahkan sampai mati di kayu salib." Yesus yang adalah hamba, taat kepada rencana agung Bapa untuk menyelamatkan dunia ini dan bahkan rela mati di atas kayu salib, tetapi bukanlah sebagai orang berdosa melainkan menanggung dosa manusia dan inilah pelayanan yang sempurna dari Yesus di mana ia melayani semua orang dan berkorban bagi semua orang.

Allah Meninggikan Dia dan Mengaruniakan Kepada-Nya Nama di Atas segala Nama

Ayat 9-11 mengatakan, "Itulah sebabnya Allah sangat meninggikan Dia dan mengaruniakan kepada-Nya nama di atas segala nama, supaya dalam nama Yesus bertekuk lutut segala yang ada di langit dan yang ada di atas bumi dan yang ada di bawah bumi,dan segala lidah mengaku: "Yesus Kristus adalah Tuhan," bagi kemuliaan Allah, Bapa!" Allah mengaruniakan kepada-Nya nama di atas segala nama karena kerendahan hati-Nya yang dinyatakan melalui kemauan-Nya menjadi hamba dan ketaatan-Nya sampai mati di atas kayu salib. Kerendahan hati adalah sesuatu yang memiliki nilai tersendiri dari semua jenis kebaikan lainnya. McDermott mengatakan,

Apakah Anda ingat George Gwynn? Ia seorang janitor (penjaga gedung) saleh. Ketika saya mengingat kembali mengapa saya dan begitu banyak orang lain yang menyukai George, saya berpikir tentang kerendahan hatinya. Bukan berarti ia tidak memiliki kualitas-kualitas menyenangkan yang lain. George bersikap ramah dan bijak dan budi baik, tetapi sifat rendah hatinya itulah yang membuat kualitas-kualitas itu lebih menarik. Tanpa sifat rendah hati kebaikannya hanya sikap yang berlebihan, kebijakannya angkuh dan perhatiannya pada orang lain sekedar memuaskan diri sendiri. Sifat rendah hatinyalah yang menambah terang - suatu terang yang kudus terhadap kebijakan-kebijakannya yang lain. ${ }^{\text {viii }}$

Ayat-ayat sebelum ayat 9 adalah alasan mengapa sehingga Allah sangat meninggikan Yesus dan mengaruniakan nama di atas segala nama. Alasannya adalah karena kerendahan hati-Nya yang dinyatakan melalui kemauan-Nya menjadi hamba dan ketaatan-Nya sampai mati di atas kayu salib.

Maksud dari "nama di atas segala nama" menurut tafsiran sabda "Ialah gelar "Tuhan", Fili 2:11, atau secara lebih mendalam Nama Allah yang tidak terungkapkan (Yahwe dalam Perjanjian Lama). Dalam kemenangan Kristus yang dibangkitkan Nama ilahi itu terungkap dalam gelar "Tuhan", bdk Kis 2:21; Kis 3:16. Nama itu terutama di atas nama segala malaikat, bdk Ef. 1:21; Ibr 1:4; 1Pe 3:22. Memang "memberi nama" berarti memberi sesuatu yang riil sekali, bdk Efe 1:21; Ibr 1:4. "'ix 


\section{KESIMPULAN}

Berdasarkan pembahasan sebelumnya, maka kesimpulan dari tulisan ini adalah sebagai berikut:

Pertama, Paulus memberikan beberapa petunjuk tentang bagaimana cara mendapatkan sukacita yang sempurna itu adalah dengan cara sehati sepikir, dalam satu kasih, satu jiwa, satu tujuan, dengan tidak mencari kepentingan sendiri atau puji-pujian yang sia-sia.

Kedua, hal yang perlu diteladani dari Kristus Yesus dalam hal kerendahan hatiNya yaitu: tidak mempertahankan kesetaraannya dengan Allah dan juga ia rela menjadi hamba yang setia dan taat kepada rencana Allah dan bahkan sampai mati di atas kayu salib. Selain kerendahan hati kekudusan juga merupakan hal yang sangat penting dan itu hanya akan terjadi jika Kristus telah menjadi juru selamat. ${ }^{x}$

Ketiga, alasan mengapa sehingga Allah sangat meninggikan Yesus dan mengaruniakan nama di atas segala nama. Alasannya adalah karena kerendahan hatiNya yang dinyatakan melalui kemauan-Nya menjadi hamba dan ketaatan-Nya sampai mati di atas kayu salib.

\section{KEPUSTAKAAN}

i DonaldC. Stamps, Alkitab Penuntun Hidup Berkelimpahan (Malang: Gandum Mas, 1996).

ii J. Wesley Brill, Tafsiran Surat Filipi (Bandung: Kalam Hidup, 1993), 54.

iii Ibid., 56.

iv Warren W. Wiersbe, Sukacita Di Dalam Kristus (Bandung: Kalam Hidup, 1999), 55.

${ }^{v}$ Stamps, Alkitab Penuntun Hidup Berkelimpahan.

${ }^{v i}$ Brill, Tafsiran Surat Filipi, 60.

vii Ibid., 60,61.

viii Gerald R. Mcdermott, Mengenali 12 Tanda Kerohanian Sejati (Yogyakarta: ANDI, 2004).

ix "Alkitab Sabda," Oktober 2019, http: //alkitab.sabda.org /commentary. php?passage=Filipi\%202:9.

x Marsi Bombongan Rantesalu, "Doktrin Kerajaan Seribu Tahun Berdasarkan Kitab Wahyu,"

Marampa' 1, no. 1 (2016): 192. 